\title{
Reminiscences of my life as a nutritionist - and looking to the future
}

Susan J Fairweather-Tait

Norwich Medical School, University of East Anglia, Norwich Research Park, Norwich NR4 7UQ, UK

s.fairweather-tait@uea.ac.uk

Iron rusts from disuse; stagnant water loses its purity and in cold weather becomes frozen; even so does inaction sap the vigour of the mind.

Leonardo da Vinci (The Notebooks of Leonardo Da Vinci, translated by Jean Paul Richter 1883 http://www.gutenberg.org/cache/epub/5000/pg5000.html)

\footnotetext{
Abstract

In this invited article for the Crystal Ball series I have tried to briefly cover my undergraduate and post-graduate training and subsequent career in nutrition, and end with some thoughts about the future. It has not been possible to give a comprehensive account of my many years of nutrition research, so I have selected a few events that might amuse readers. Also, due to lack of space, I have been unable to mention all the wonderful colleagues and friends with whom I have interacted, but, if they read this article, they know who they are... Unfortunately, a growing number are no longer with us and I would like to pay tribute to them and their important contribution to human nutrition.
} 


\section{Early days}

2 Food played an important part in my early life, being the daughter of a grocer, but I

only became aware of the discipline of nutrition when I was an undergraduate food scientist at Queen Elizabeth College (QEC). The Nutrition Department at QEC was one of the best in the world, with many inspiring lecturers, and this is where my passion for nutrition originated. I was fortunate to be accepted by Professor Arnold Bender as a PhD student, subject to passing the Masters in Nutrition, and very grateful to the Head of Department, Professor Stewart Truswell, for insisting that I had a thorough and comprehensive training in nutrition before launching into my speciality area of research. I chose to study factors affecting iron bioavailability after reading an interesting article in the BMJ on the effect of gastric mucopolysaccharide on iron absorption by Professor Alan Jacobs [1].

Professor Bender was a great PhD supervisor - he allowed me total freedom to undertake experiments designed to address the many intriguing questions relating to iron availability. He shared endless interesting anecdotes and had widespread connections throughout the world of nutrition and food science, thanks to which I secured a part-time job teaching nutrition to catering students at Middlesex Polytechnic and ran adult education classes at City University, both of which were great experiences for a PhD student and boosted my meagre stipend. One invaluable lesson I learnt was to look carefully through slides before using them. Professor Bender kindly lent me a set of slides depicting nutritional deficiencies, which I used for an adult evening class, mostly attended by middle-class women (the group we might today refer to as the 'worried well'). Unfortunately, I had no idea that these included graphic photographs of naked babies with vitamin and mineral 
deficiencies (e.g. acrodermatitis enteropathica) and a post-mortem photograph of a baby who had died of marasmus. The room became very silent when I showed these slides, and unsurprisingly attendance dropped the following week. Apart from allowing me to learn through my own mistakes, Professor Bender had an amazing ability to look at a page of data in my lab book and find, within seconds, any errors in the midst of all the numbers. Thanks to the vibrant postgraduate community at QEC I was exposed to a wide variety of research techniques, although one 'exposure' was rather unfortunate. I was macerating rat carcasses, labelled with ${ }^{59} \mathrm{Fe}$ and ${ }^{55} \mathrm{Fe}$ from iron absorption experiments, when the macerator lid flew open (the extract pipes had been blocked by the person before me putting paper down the macerator) and I was showered with radioactive sludge! This was when I began to consider the alternative of using stable isotopes for iron absorption studies.

At the end of my PhD, Professor Bender introduced me to Professor John Dickinson, who was looking for an RA at Surrey. I applied for the post, but had not read the letter inviting me to an interview carefully enough and was late. Not surprisingly, I was not offered the job, but luckily Donald Hicks, with whom I had undertaken a summer project, offered me a job with Beecham Products to work on Horlicks, Ribena and Lucozade. It was very educational working for the food industry, although I had to put up with Donald calling me "the iron lady", presumably because my father was a grocer, I had a degree in Food Science, and my PhD was on iron, but there, I hope, the similarity with Margaret Thatcher ends.

About a year after joining Beecham Products, I attended a Food Science and Technology conference in Japan, and during the post-congress tour I met Frank 
Curtis. He told me about a new Nutrition Division that David Southgate was setting up at the Food Research Institute (FRI) in Norwich. He suggested I visited to talk about jobs. When we got to Heathrow airport and were all saying goodbye, I summoned the courage to ask if he would mind 'putting in a good word for me' with David Southgate, and he handed me his card. I was so embarrassed to find he was the new FRI director. I eventually went to Norwich to meet David Southgate and took my mother with me as my parents lived in Norfolk. I left her in the car, saying I wouldn't be long because I wasn't thinking about leaving Beecham's, but emerged after quite some time feeling very excited. It was mid-winter and she was cold but forgave me when she learnt that I was considering moving closer to home. I applied for one of the vacancies when they were advertised and this was the beginning of my long career at the Institute in Norwich.

\section{From radio- to stable isotopes}

When I started working at FRI (later to be renamed the Institute of Food Research) the funding body, the Agricultural Research Council (later to be renamed the Agricultural and Food Research Council, and then the BBSRC), forbade work on humans as this was considered to be MRC territory, and I had to use animal models. Initially, with Professor David Southgate's interest in dietary fibre, we demonstrated that phytate (not fibre per se) reduced iron bioavailability [2, 3]. We commissioned a small animal whole body counter that had to be built from low radioactive steel, for which a scuttled Scapa Flow German WW1 Battleship was located. The counter worked well and we completed a number of experiments measuring factors that affect iron absorption, including the effect of timing of an iron dose on subsequent iron absorption [4]. Our findings stimulated Fernando Viteri to undertake research on 
different dosing regimens for iron [5], which resulted in new WHO guidelines for pregnant women. They recommend intermittent oral iron and folic acid supplementation with $120 \mathrm{mg}$ of elemental iron and $2800 \mu \mathrm{g}(2.8 \mathrm{mg})$ folic acid once weekly for pregnant women to improve maternal and neonatal outcomes if daily iron is not acceptable due to side effects, and in populations with an anaemia prevalence among pregnant women of less than $20 \%$ [6]. A recent Cochrane review concluded that in comparison with daily supplementation, the intermittent provision of iron supplements is probably as effective as daily iron in preventing or controlling anaemia and it has fewer side effects [7]. The translation of our early (1984) research into a new (2016) improved policy for iron supplementation is very rewarding.

Since rodents are not an ideal model for studying iron bioavailability, we tried ferrets and guinea pigs but with little success. Next, knowing that pigs are a good model for the human gut, we bought some mini-pigs from Leeds University. We transported them back to Norwich in a cardboard box in an Institute car, in total ignorance of livestock regulations. This was our first problem. The second problem became apparent as the piglets grew ... and grew. I was informed that they were several generations on from the original mini-pigs from the Yucatan, so their phenotype was changing. The stainless steel metabolic crates that I had specially built to house them so we could undertake short-term balance experiments were obviously going to be too small, and the pigs began to eat the concrete walls of the animal house, so they had to go. Fortunately, as this door closed another one opened, namely the rules about using human volunteers changed and ARC Institutes were allowed to do research on human subjects. The ARC was charged with focusing on health 
whereas the MRC would carry out research on nutrition and disease; thus was nutrition divided between the two research councils, although it does sometimes fall in the crack between the two.

David Southgate rapidly established a Human Research Ethics Committee at IFR and we began to undertake studies in human volunteers. I established a collaboration with Margaret Minski from Silwood Park, Imperial College, who could measure stable isotopes by neutron activation analysis. We undertook our first human study at IFR using stable isotopes with support from my MSc supervisor at QEC, David Richardson, who was then working for Cadbury Schweppes in Reading. The aim was to compare the bioavailability of two types of iron (ferrous sulphate and ferric phosphate) commonly used to fortify foods, when added to a malted cocoa drink. We measured iron absorption using faecal monitoring, but my first human study using stable isotopes was almost a disaster because the autoclave (that I used to make the faecal material safe for subsequent processing) over-heated and the plastic bags split. I spent several hours removing faecal slurry from the autoclave with help from good colleagues who have never forgotten the experience, but still speak to me. Thankfully, the volunteers generously agreed to repeat the absorption test, and we were able to demonstrate that the two forms were equally well absorbed [8]. I had another bad experience with the faecal monitoring technique when I undertook an iron absorption study in the Gambia [9]. On X-raying the bags containing autoclaved faeces to count the number of radio-opaque pellets (which were given in capsules to determine the completeness of faecal collection), I found at least one bag with more pellets than the volunteer had been given. Subsequent detective work revealed that some of the volunteers were swapping bags, without 
realising that each had been given a set of bags with a unique number. It turned out that the number meant nothing to them because some were unable to read, and I had not thought about this, even though they signed the consent form with a cross. Mea culpa.

Eventually, thanks to the development of more sensitive methods for detecting stable isotopes using mass spectrometry, I was able to replace the faecal monitoring technique with blood isotope ratio measurements [10]. The next 10+ years was the golden era of stable isotope research. With generous funding from the Food Standards Agency, together with EU and other grants, and a wonderful multidisciplinary team of scientists at IFR plus fantastic collaborators from Europe and worldwide, we studied the metabolism of several minerals (calcium, zinc, selenium, copper, and cadmium) and continued research on iron bioavailability. When it was not possible to extrinsically label minerals in foods, we grew plants hydroponically and intrinsically labelled them with stable isotopes. We also labelled fish with stable isotopes of selenium but, as long ago as 2004 , climate change had an impact on our research. The codfish were in tanks at the MAFF laboratories in Lowestoft into which seawater was pumped, but we had a very hot summer and the sea became very warm, resulting in some of the valuable, isotopically-labelled fish leaping out of the top of the tank. Fortunately, their unanticipated voyage was discovered in time to rescue sufficient fish to undertake our human study [11].

\section{Moving on from stable isotopes}

In 2005-6, major structural changes took place in the Institute and the departments were abolished. As a now ex-Head of Department I realised it was time to move on, 
although leaving my excellent research group and the Institute, my 'family' for over 25 years, was a real wrench. I was grateful to be given a position at UEA, and became Professor of Mineral Metabolism in 2007. At first, I was able to continue undertaking stable isotope studies because the mass spectrometer and the scientist who operated the machine also moved to UEA, but this situation was short-lived because he soon went to New Zealand, taking the mass spectrometer with him, attracted by the beautiful scenery and opportunities outside nutrition e.g. forensic science. Our last stable isotope study, completed in 2010 , showed that low $\mathrm{pH}$ beverages do not affect native non-haem iron absorption but whether they enhance iron absorption from partially soluble fortification iron (through increased solubility) remains to be tested [12]. I made use of the cell culture facilities at UEA, which, with the help of PhD students, provided me with an opportunity to undertake mechanistic studies on iron metabolism using Caco-2 cells $[13,14,15]$. I also belonged to an EU Network of Excellence (EURRECA) and worked with a dedicated team of scientists at UEA who undertook systematic searches and reviews aimed at characterising the links between micronutrient intake, status and health. In 2009, I was delighted to be appointed an Expert for the European Food Safety Authority (EFSA) NDA Panel, which entailed regular trips to Parma, Italy. This was a very worthwhile and enjoyable commitment, providing me with a great learning experience, in particular participating in the Working Groups on Health Claims and Dietary Reference Values (DRVs). In the process of updating the DRVs it became apparent to us that there are enormous gaps in knowledge, not only in our fundamental understanding of nutrient metabolism but also in the levels of intake required for optimal health, namely preventing deficiency and reducing the risk of chronic diseases. Then there is the added complication of individual variability, which has to be taken into account 
when setting values for population groups, and requires an appreciation of the importance of quantifying uncertainty for risk assessment.

In setting the DRVs for iron, we had to select a value for dietary iron bioavailability, and because EFSA is committed to produce transparent reports, the DRV WG had to provide an evidence-based value for iron bioavailability. Fortunately, I had been working on this problem for some time with a statistician, Jack Dainty, who was developing a probability model to predict dietary iron bioavailability [16] and we managed to publish this in time for EFSA to use it for the iron DRVs [17]. We subsequently refined the model using data from Ireland [18] and, more recently, we collaborated with ETH Zurich to make use of data collected in Benin, and we were able to validate the model prediction using the stable isotope absorption data [19]. We believe this is the best approach for deriving country-specific values for dietary iron bioavailability for setting DRVs and for developing public health policies to reduce the risk of iron deficiency.

There have been two main drivers behind my research at UEA, both of which relate to public health problems and therefore priority areas for funding (a) the demographics of ageing and the role of nutrition in preventing non-communicable diseases, and (b) ways to improve the nutritional quality of plant foods. I helped develop a proposal, coordinated by the University of Bologna, for a one-year intervention trial in elderly Europeans from five different countries (NU-AGE). The aim was to provide tailored individual advice (to maximise compliance) to adopt a Mediterranean-style diet and the primary end-point was inflammatory status. We have published various papers on secondary end-points, including positive effects of 
201 the Mediterranean diet on bone health [20] and blood pressure [21] but no effect on

202

203

204

205

206

207

208

209

210

211

212

213

214

215

216

217

218

219

220

221

222

223

224

225 iron and selenium status [22]. I have also collaborated with plant scientists, including Janneke Balk at JIC, examining iron bioavailability in vegetables, and the potential of pea ferritin as a plant supply of iron [23].

\section{My heroes}

In the company of many of my contemporaries, I considered Elsie Widdowson to be an inspirational nutritionist. She undertook research in so many fundamental areas, and her approach and interpretation provided unique insights into nutritional science, with just rudimentary tools and techniques as her disposal. This is such a contrast from today where we are data rich, but making only incremental increases in our understanding of nutrition. However, it is only fair to point out that most of the major questions in nutrition have been answered, and we are now left with the more difficult, and sometimes intransigent, problems to solve.

In the early days of iron research, my three heroes were Thomas Bothwell, Jim Cook and Leif Hallberg. I had the honour of being selected for a SUSTAIN Task Force evaluating the usefulness of elemental iron for cereal fortification [24] and in 2000 I was invited to a workshop in Monterrey, Mexico, at which my heroes were present, together with other international experts. I arrived late at night and set my alarm clock ready for the morning meeting, but instead I was woken by the telephone call in my hotel room asking where I was. I had set the $24 \mathrm{~h}$ time on my alarm clock incorrectly (a 'Mainwaring' moment for fans of Dad's Army), and had the embarrassing task of explaining to my heroes why I was 2 hours late for the meeting! Since those early years, I have thoroughly enjoyed working with so many people, 
including staff at IFR and UEA, PhD students, and national/international collaborators. I am particularly indebted to Ros Gibson, Janet King and Christine Williams, each of whom has been kind enough to give me significant personal support at different stages of my career.

\section{The Crystal Ball}

Nutrition is of considerable interest to consumers and attracts a great deal of media attention, some of which is sometimes unwelcome as it confuses the public and results in general mistrust of nutrition advice. A great deal of emphasis is placed on nutritional epidemiology because it is almost impossible to undertake RCTs (the highest level of evidence) for a long enough period of time, sufficient to test for causal relationships, hence the urgent need to develop more early biomarkers for risk of chronic diseases, together with more accurate measures of habitual diet. Furthermore, designing a 'clean' nutrition intervention, unlike drug trials where placebos and drugs are blinded and everything else remains unchanged, is difficult. Intervening with one aspect of the diet invariably has an effect on other dietary constituents, and sophisticated statistical procedures are required to take into account possible effects from these other changes. Nutritional epidemiology is only able to identify associations, not cause and effect, and the findings are sometimes misinterpreted and can lead to conflicting messages, but it is important for the public to have consistent dietary advice to persuade them to take it seriously.

There is general agreement about what constitutes a 'healthy' diet at the population level, but individuals differ in their response to diet, and the reasons for this needs to be understood so that personalised nutrition has a more robust basis. It is 
anticipated that future GPs will be provided with genotype profiles and they will need to link these data to appropriate dietary recommendations, as well as other lifestyle options, in order to manage their patients' health and reduce the risk of disease. The current culture to diagnose and treat patients must embrace more emphasis on prevention, because although this is more long-term, it will benefit both patients and the health service. Increasing the quality of life should replace longevity as one of the primary goals of medicine.

External drivers are going to have a major influence on our lifestyle. Climate change and food security mean that plants will have a more important role in future. Red meat consumption will fall, not only driven by adverse effects on health because the evidence for this is surprisingly weak [25], but to help counteract global warming. As meat is an important source of bioavailable iron, this may increase the prevalence of anaemia, already estimated to affect one third of the world's population with irondeficiency anaemia being the most common aetiology [26]. Plant scientists now include nutritional quality amongst the traits for which they are breeding, and I have been peripherally involved in biofortification programmes supported by HarvestPlus, mainly to do with iron and zinc bioavailability, which have been running for a number of years. Last year I was delighted to be invited to collaborate on a BBSRC-funded project measuring iron and zinc absorption from biofortified potatoes grown in Peru. One of my early experiments at IFR was measuring iron absorption from potatoes by rats [27] and I am fortunate to be collaborating with Michael Zimmermann's laboratory at ETH Zurich, so it feels like I am closing a circle. It also means that I will be following Leonardo da Vinci's advice (see quote above). 
276 Finally, as diet and health moves forward into the 'systems' era, it is important to

277 remember that the building blocks for nutrition, namely nutrient requirements, are still

278 not fully secure. Gaps have been identified as part of the process of deriving DRVs,

279 many of which require mechanistic research, using physiological, biochemical and

280 molecular biology techniques in conjunction with the newer-omics technologies. We

281 need accurate values for nutrient requirements, both at an individual level to devise

282 strategies for personalised nutrition, and at the population level to develop effective

283 public health policies. Designing human studies to generate the information required

284 will be a challenge, but if we build the diet and health edifice too high on shaky

285 foundations, we may live to regret our haste. My surveyor husband has taught me to

286 appreciate that solid foundations are essential for any building, and this maxim is

287 equally applicable to nutrition research, training, and the application of nutrition

288 knowledge.

289

290 Compliance with ethical standards

291 Conflict of interest: the author declares no conflict of interest. 


\section{References}

1. Jacobs A, Miles PM. Intraluminal transport of iron from stomach to small-intestinal mucosa. BMJ 1969; 4: 778-781.

2. Caprez A, Fairweather-Tait SJ. The effect of heat treatment and particle size of bran on mineral absorption in rats. Br J Nutr 1982; 48: 461-467.

3. Fairweather-Tait. The effect of different levels of wheat bran on iron absorption in rats from bread containing similar amounts of phytate. Br J Nutr 1982; 47: 243-249.

4. Fairweather-Tait SJ, Wright AJ. The influence of previous iron intake on the estimation of bioavailability of Fe from a test meal given to rats. Br J Nutr 1984; 51 : 185-191.

5. Viteri FE. Iron supplementation for the control of iron deficiency in populations at risk. Nutr Rev 1997; 55: 195-209.

6. WHO recommendations on antenatal care for a positive pregnancy experience. Geneva: World Health Organization; 2016

\section{(https://www.who.int/elena/titles/intermittent iron pregnancy/en/ accessed} 19/11/2019)

7. Fernández-Gaxiola AC, De-Regil LM. Intermittent iron supplementation for reducing anaemia and its associated impairments in adolescent and adult menstruating women. Cochrane Database Syst Rev. 2019 Jan 31;1:CD009218. 8. Fairweather-Tait SJ, Minski MJ, Richardson DP. Iron absorption from a malted cocoa drink fortified with ferric orthophosphate using the stable isotope $58 \mathrm{Fe}$ as an extrinsic label. Br J Nutr 1983; 50: 51-60.

9. Fairweather-Tait SJ, Minski MJ, Singh J. Non-radioisotopic method for measuring iron absorption from a Gambian meal. Am J Clin Nutr 1987; 46: 844-848. 
10. Fairweather-Tait S, Fox T, Wharf SG, Eagles J. The bioavailability of iron in different weaning foods and the enhancing effect of a fruit drink containing ascorbic acid. Pediatr Res 1995; 37: 389-394.

11. Fox TE, Atherton C, Dainty JR, Lewis DJ, Langford NJ, Baxter MJ et al. Absorption of selenium from wheat, garlic, and cod intrinsically labeled with Se-77 and Se-82 stable isotopes. Int J Vitam Nutr Res 2005; 75: 179-186.

12. Collings R, Fairweather-Tait SJ, Dainty JR, Roe MA. Low-pH cola beverages do not affect women's iron absorption from a vegetarian meal. J Nutr 2011; 141: 805808.

13. Thompson BA, Sharp PA, Elliott R, Fairweather-Tait SJ. Inhibitory effect of calcium on non-heme iron absorption may be related to translocation of DMT-1 at the apical membrane of enterocytes.J Agric Food Chem 2010; 58: 8414-8417. 14. Perfecto A, Elgy C, Valsami-Jones E, Sharp P, Hilty F, Fairweather-Tait S. Mechanisms of iron uptake from ferric phosphate nanoparticles in human intestinal Caco-2 cells. Nutrients 2017; 9: pii: E359. doi: 10.3390/nu9040359.

15. Perfecto A, Rodriguez-Ramiro I, Rodriguez-Celma J, Sharp P, Balk J, Fairweather-Tait S. Pea ferritin stability under gastric $\mathrm{pH}$ conditions determines the mechanism of iron uptake in Caco-2 cells. J Nutr 2018;148: 1229-1235.

16. Dainty JR, Berry R, Lynch SR, Harvey LJ, Fairweather-Tait SJ. Estimation of dietary iron bioavailability from food iron intake and iron status. PLoS One. 2014 Oct 30; 9: e111824. doi: 10.1371/journal.pone.0111824. eCollection 2014.

17. EFSA NDA Panel (EFSA Panel on Dietetic Products, Nutrition and Allergies), 2015. Scientific Opinion on Dietary Reference Values for iron. EFSA Journal 2015;13(10):4254, 115 pp. doi:10.2903/j.efsa.2015.4254 . 
18. Fairweather-Tait SJ, Jennings A, Harvey LJ, Berry R, Walton J, Dainty JR. Modeling tool for calculating dietary iron bioavailability in iron-sufficient adults. Am J Clin Nutr 2017; 105: 1408-1414.

19. Fairweather-Tait S, Speich C, Mitchikp`CES, Dainty JR. Dietary iron bioavailability: a simple model that can be used to derive country-specific values for adult men and women. Food and Nutrition Bulletin 2019 Nov 20:379572119885482. doi: 10.1177/0379572119885482 [Epub ahead of print].

20. Jennings A, Cashman KD, Gillings R, Cassidy A, Tang J, Fraser W et al. A Mediterranean-like dietary pattern with vitamin D3 (10 $\mathrm{gg} / \mathrm{d})$ supplements reduced the rate of bone loss in older Europeans with osteoporosis at baseline: results of a 1y randomized controlled trial. Am J Clin Nutr 2018; 108: 633-640.

21. Jennings A, Berendsen AM, de Groot LCPGM, Feskens EJM, Brzozowska A, Sicinska E et al. Mediterranean-style diet improves systolic blood pressure and arterial stiffness in older adults. Hypertension 2019; 73: 578-586.

22. Jennings A, Tang J, Gillings R, Perfecto A, Dutton J, Speakman J et al. Changing from a Western to a Mediterranean-style diet does not affect iron or selenium status: results of the New Dietary Strategies Addressing the Specific Needs of the Elderly Population for Healthy Aging in Europe (NU-AGE) 1-year randomized clinical trial in elderly Europeans. Am J Clin Nutr. 2019 Sep 26. pii: nqz243. doi: 10.1093/ajcn/nqz243. [Epub ahead of print].

23. Perfecto A, Rodriguez-Ramiro I, Rodriguez-Celma J, Sharp P, Balk J, Fairweather-Tait S. Pea ferritin stability under gastric $\mathrm{pH}$ conditions determines the mechanism of iron uptake in Caco-2 cells. J Nutr 2018; 148: 1229-1235.

24. Hurrell R, Bothwell T, Cook JD, Dary O, Davidsson L, Fairweather-Tait S et al. The usefulness of elemental iron for cereal flour fortification: a SUSTAIN Task Force 
report. Sharing United States Technology to Aid in the Improvement of Nutrition. Nutr Rev 2002; 60: 391-406.

25. Johnston BC, Zeraatkar D, Han MA, Vernooij RWM, Valli C, Dib RE et al. Unprocessed Red Meat and Processed Meat Consumption: Dietary Guideline Recommendations From the Nutritional Recommendations (NutriRECS) Consortium. Ann Intern Med 2019; 171: 756-764.

26. Kassebaum NJ, Jasrasaria R, Naghavi M, Wulf SK, Johns N, Lozano R et al. A systematic analysis of global anemia burden from 1990 to 2010. Blood 2014; 123 : $615-624$.

27. Fairweather-Tait SJ. Studies on the availability of iron in potatoes. $\mathrm{Br} \mathrm{J}$ Nutr 1983; 50: 15-23. 